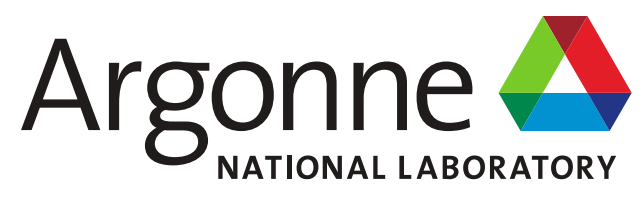

ANL/RTR/TM-19/13

\title{
Addendum to the REBUS Users Guide: REBUS-PC Version 1.5
}

Nuclear Science \& Engineering Division 
About Argonne National Laboratory

Argonne is a U.S. Department of Energy laboratory managed by UChicago Argonne, LLC under contract DE-AC02-06CH11357. The Laboratory's main facility is outside Chicago, at 9700 South Cass Avenue, Argonne, Illinois 60439. For information about Argonne and its pioneering science and technology programs, see www.anl.gov.

\section{DOCUMENT AVAILABILITY}

Online Access: U.S. Department of Energy (DOE) reports produced after 1991 and a growing number of pre-1991 documents are available free via DOE's SciTech Connect (http://www.osti.gov/scitech/)

Reports not in digital format may be purchased by the public from the National Technical Information Service (NTIS):

U.S. Department of Commerce

National Technical Information Service 5301 Shawnee Rd

Alexandria, VA 22312

www.ntis.gov

Phone: (800) 553-NTIS (6847) or (703) 605-6000

Fax: (703) 605-6900

Email: morders@ntis.gov

Reports not in digital format are available to DOE and DOE contractors from the Office of Scientific and Technical Information (OSTI):

U.S. Department of Energy

Office of Scientific and Technical Information

P.O. Box 62

Oak Ridge, TN 37831-0062

www.osti.gov

Phone: (865) 576-8401

Fax: (865) 576-5728

Email: reports@osti.gov

Disclaimer

This report was prepared as an account of work sponsored by an agency of the United States Government. Neither the United States Government nor any agency thereof, nor UChicago Argonne, LLC, nor any of their employees or officers, makes any warranty, express or implied, or assumes any legal liability or responsibility for the accuracy, completeness, or usefulness of any information, apparatus, product, or process disclosed, or represents that its use would not infringe privately owned rights. Reference herein to any specific commercial product, process, or service by trade name, trademark, manufacturer, or otherwise, does not necessarily constitute or imply its endorsement, recommendation, or favoring by the United States Government or any agency thereof. The views and opinions of document authors expressed herein do not necessarily state or reflect those of the United States Government or any agency thereof, Argonne National Laboratory, or UChicago Argonne, LLC. 
ANL/RTR/TM-19/13

\section{Addendum to the REBUS Users Guide: REBUS-PC Version 1.5}

prepared by

A. P. Olson

M. A. Smith

Nuclear Science \& Engineering Division, Argonne National Laboratory

September 2019 
(This page left intentionally blank) 


\section{Executive Summary}

The Depart of Energy (DOE) National Nuclear Security Administration (NNSA) Material Management and Minimization (M3) Reactor Conversion Program uses the REBUS-PC computer code to provide reactor physics and core design information such as neutron flux distributions in space, energy, and time, and to track isotopic changes in fuel and neutron absorbers with burnup. REBUS-PC has evolved from the original REBUS code, which was created starting in the 1960's to study large liquid metal cooled fast reactors. In particular, additional outputs were added to improve user convenience and some inputs were modified to improve the functionality of the software. REBUS and REBUS-PC both model the external cycle, and are very general codes with 1D, 2D, and 3D neutronics capabilities, and with complete fuel shuffling capabilities.

REBUS remains an extremely efficient reactor analysis tool for use in fast reactor systems, and so development has continued at Argonne National Laboratory (ANL) to this day for non-thermal reactor applications. While retaining the efficient computational engine of REBUS, REBUS-PC has evolved to its present status with continuous development since 1999. REBUS-PC has numerous changes and enhancements directed toward the needs of the thermal reactor analyst using Windows or Linux-based computational platforms. 


\section{Table of Contents}

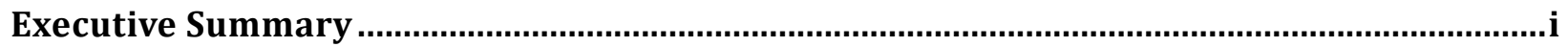

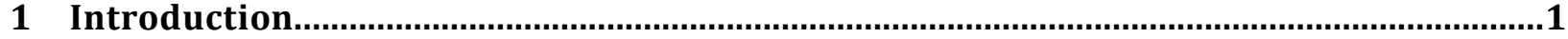

1.1 REBUS-PC Development History ………................................................................................. 1

1.2 REBUS-PC Software Changes Relative to REBUS ……................................................................. 2

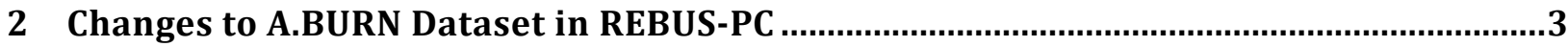

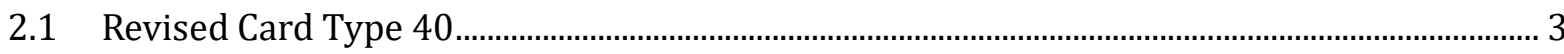

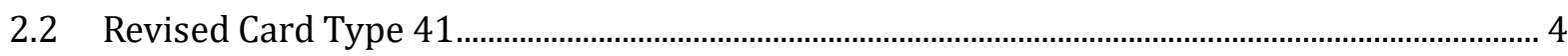

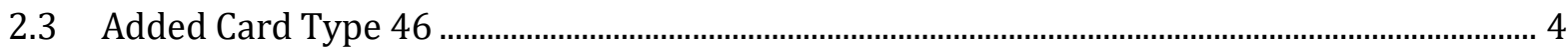

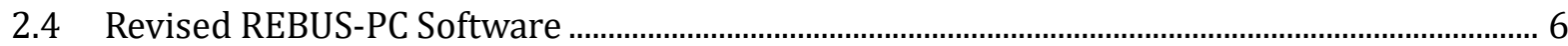

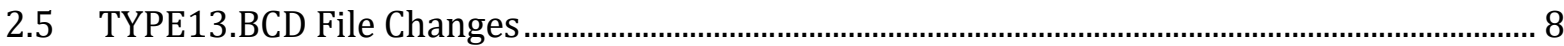

2.6 Suggested User Conventions …………............................................................................................ 9

3 Verification of the REBUS-PC Modifications …............................................................. 11

3.1 Verification of the Cubic Spline Fit of Burnup-Dependent Cross Sections ................................11

3.2 Verification of the TYPE13.BCD Dataset.......................................................................................... 12

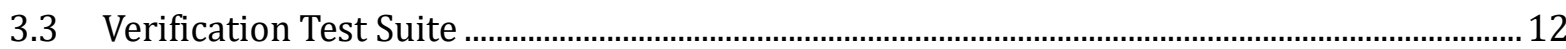

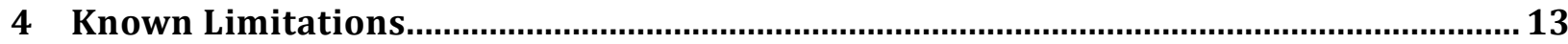

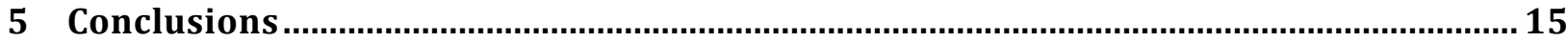

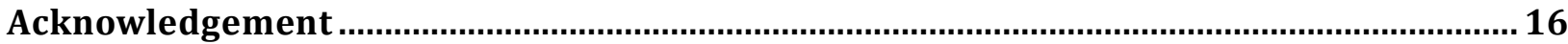

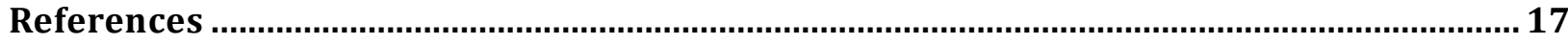

APPENDIX: A.BURN DATASET CHANGES...................................................................................... 18 


\section{List of Figures}

Figure 2-1. Truncated Description of Card Type \#40 in A.BURN ……........................................................... 3

Figure 2-2. Truncated Description of Card Type \#40 in A.BURN ...................................................................... 4

Figure 2-3. Truncated Description of Card Type \#46 in A.BURN ……............................................................. 5

Figure 2-4. Sample Input Card Type \#41 and \#46 Inputs for A.BURN ............................................................ 5

Figure 2-5. Sample Output Excerpt When Using Card Type \#41 and \#46 Inputs for A.BURN................ 6

Figure 4-1. Output Termination Message from REBUS-PC for Memory Fault Error..................................13 


\section{List of Tables}

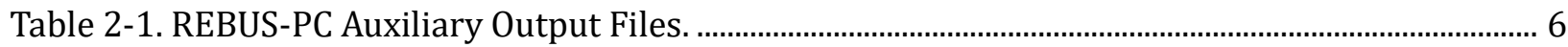

Table 3-1. Eigenvalue Results Using Burnup-Dependent Cross Sections .....................................................12 


\section{Introduction}

Since its conception in the 1960's, REBUS (the REactor BUrnup System) [1-5] has been a generalpurpose fuel cycle analysis tool in that it not only modeled fuel burnup during operation, but also allowed for fuel fabrication with a core criticality enrichment search, multiple fuel feed sources and flexible reprocessing plant scenarios. The primary development focus of REBUS was for fast spectrum reactor systems. Most of the REBUS software is written in either Fortran 66 or Fortran 77. The REBUSPC code is an offshoot from REBUS v. $3.0[4,5]$ and has many modifications to refocus the fuel cycle analysis capability to do design and analysis work on thermal spectrum reactors and adapt it to modern desktop computing systems running Windows. REBUS-PC development was initiated in 1999 by the Reduced Enrichment for Research and Test Reactors (RERTR) Program, and is now continued to support work within the U.S. Department of Energy (DOE) National Nuclear Security Administration (NNSA) Material Management and Minimization (M3) Program.

Development of the original REBUS software has also continued at Argonne National Laboratory (ANL), in parallel with REBUS-PC development. The latest manual of REBUS, Reference 5, is significantly out of date with regard to both the present version of REBUS-11 and REBUS-PC. This manuscript documents only the aspects of the software which were modified and enhanced within the REBUS-PC development. For information on the methodology that is not covered by this manuscript, the reader is referred to References 4 and 5 for more detailed discussion.

\subsection{REBUS-PC Development History}

Because of the low memory capabilities of past computing technology, the REBUS software was designed to be a set of executables that were ran in concert, which is referred to as a modular code design. To accomplish this, interface files are used to transfer data between the executables, all of which are controlled by the specialized Argonne Reactor Code (ARC) system routines for file management and input processing. The RERTR program initially focused on developing REBUS-PC as a more distributable piece of software with collaborators through the use of the Lahey Fortran 95 compiler for Windows [8]. The original multi-executable concept was eliminated by source code changes to change executable driver routines into subroutines giving a single executable. With the Lahey compiler, the REBUS-PC software was demonstrated to operate efficiently in the Windows environment even for very large (memory) problems.

REBUS was originally programmed to run on large main-frame computers, which at the time had "small core memory" and "large core memory" such that the software developer was responsible for programming the efficient use of the memory space and the transfer between those memory spaces. With respect to today's architecture, the L1 through L3 cache of most chips (combined typically $<<$ $100 \mathrm{MB}$ ) can be considered the "small core memory", while the off-chip motherboard memory is the large core memory ( $>16$ GB by today's standard). The memory management today has been transferred to a software layer available through the installed operating system which is introduced by the compiler. This software layer is designed to maximize the lifetime of the memory chips and performance of the machine and eliminates the need for the memory control infrastructure that is in both REBUS and REBUS-PC. 


\subsection{REBUS-PC Software Changes Relative to REBUS}

To fully describe the additional software changes between REBUS and REBUS-PC, the following list summarizes the unique features of REBUS-PC (beyond the preceding mentioned modifications to allow it to execute on the Windows platform). It is important to note that with some of the modifications, several of the older REBUS uses, such as the equilibrium mode model, are not working as those features are not needed for the thermal spectrum analysis work of interest. Those details are deferred to later in this manuscript.

1) The A.BURN data set was modified to include spline based cross section interpolation routines. While the existing polynomial scheme is very appropriate for fast spectrum systems, for thermal spectrum systems, the severe isotopic shift in the energy self-shielding of capture and fission resonances at low burnup causes the polynomial scheme to produce non-physical results which the linear and cubic spline techniques resolve quite easily.

2) A Wrapup/Restart capability was functionally made to work using ASCII based interface files. The original REBUS wrapup/restart capability for binary files was essentially unchanged, while a new file, RESTRT.BCD, was created in order to save all of the many new text files with names of the form *.BCD.

3) To make multi-use (10-20 different fuel cycles) fuel assemblies practical in large fuel cycle models, the TYPE13.BCD file was added and the edits extended such that A.NIP3 card types 13,14 , and 15 are provided at each time node, including active and inactive isotopes. Card Type 35 data for dataset A.BURN is also provided. The user can thereby easily construct a new REBUS problem by assigning each assembly a unique zone and manipulate the assignment of that zone to a geometric region during consecutive REBUS-PC fuel cycle calculations.

4) The original REBUS input was created by engineers on paper "Fortran data cards" and feed into a card reader. It should come as no surprise that a practical limit of 999,999 cards was set at the beginning of the REBUS development and instituted in the ARC System. The same limit was applied to each input card type in each data set (card type 01 is a comment while card type 14 is used to define a composition as an example). It should also come as no surprise that a full 3D model of a complex thermal spectrum reactor can easily extend beyond this limit for just the composition definition (100 isotopes per zone and 10000 depletable zones in a single cycle loading) alone. In REBUS-PC, the hardwired limits were extended to $99,999,999$ by changing 30 subroutines.

5) The ARC system control was designed to provide for multiple input case execution capability. In this setup, the user can provide the fuel cycle input for three consecutive fuel loadings where the second and third inputs only consist of defining the changes to the first input rather than repeat the entire data set. REBUS-PC is the first version of REBUS that allows this functionality to be used. This required significant changes to the REBUS driver.

6) The STACK file is a unique aspect of REBUS where the data files for each time point are written consecutively to a single data file as opposed to written to unique files by time point. This was done for convenience on the early computing architectures. The REBUS-PC software marks the first time the user was given input controls to restrict the size of the STACK file and instead rely upon the previously mentioned equivalent ASCII files. 


\section{Changes to A.BURN Dataset in REBUS-PC}

The bulk of the changes visible to the user are in the input and output. Because the A.NIP3 dataset does not change, the only real input changes occur with the A.BURN dataset which is the focus of this section. All of the updated input datasets are provided in the Appendix to this report.

\subsection{Revised Card Type $\mathbf{4 0}$}

The type 40 input card for A.BURN controls the polynomial least squares criteria. A summary description of this card type is provided in Figure 2-1.

\begin{tabular}{|c|c|c|}
\hline $\begin{array}{l}\#+2 \\
==\end{array}$ & $\begin{array}{l}\text { COLUMNS } \\
======\end{array}$ & 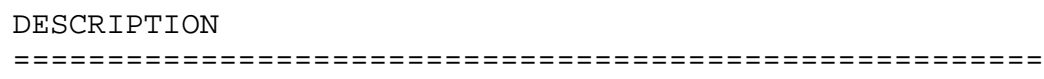 \\
\hline$\odot 2$ & $7-12$ & LABEL OF BURNUP DEPENDENT ISOTOPE \\
\hline 03 & $13-18$ & INDEX NUMBER OF REACTION \\
\hline \multirow[t]{3}{*}{03} & $13-18$ & ๑...CAPTURE CROSS SECTIONS \\
\hline & & 1...FISSION CROSS SECTIONS \\
\hline & & 2...BOTH CAPTURE AND FISSION CROSS SECTIONS \\
\hline$\odot 4$ & $19-30$ & ALLOWABLE ERROR IN CROSS SECTION DATA FIT \\
\hline$\odot 5$ & $31-36$ & MAXIMUM ORDER FOR THE POLYNOMIAL FIT (DEFAULT=8) \\
\hline$\odot 6$ & $37-42$ & LABEL OF BURNUP DEPENDENT ISOTOPE \\
\hline \multirow[t]{3}{*}{07} & $43-48$ & ○...CAPTURE CROSS SECTIONS \\
\hline & & 1...FISSION CROSS SECTIONS \\
\hline & & 2... BOTH CAPTURE AND FISSION CROSS SECTIONS \\
\hline$\odot 8$ & $49-60$ & ALLOWABLE ERROR IN CROSS SECTION DATA FIT \\
\hline$\odot 9$ & $61-66$ & MAXIMUM ORDER FOR THE POLYNOMIAL FIT (DEFAULT=8) \\
\hline
\end{tabular}

Figure 2-1. Truncated Description of Card Type \#40 in A.BURN

As mentioned previously, the polynomial approximation is acceptable for fast spectrum reactors, but due to the large change in equivalence theory multi-group capture and fission cross sections in thermal spectrum reactors at low burnup, a linear and cubic spline treatment was implemented in addition to the existing polynomial treatment. Additionally, the application was extended to include capture, fission, (n,p), (n,alpha), (n,deuteron), or (n,tritium) processes, where the previous approach only allowed capture and fission. Consequently, inputs \#3 or \#7 on card type 40 can now take on the following values:

$\begin{array}{ll}0 & \text { capture (n,gamma) by polynomial fit } \\ 1 & \text { fission (n,f) by polynomial fit } \\ 2 & \text { both (n,gamma) and (n,f) ) by polynomial fit } \\ 11 & \text { (n,gamma) by piece-wise linear (degenerate spline) } \\ 12 & \text { (n,f) by piece-wise linear } \\ 13 & \text { (n,p) by piece-wise linear } \\ 14 & \text { (n,alpha) by piece-wise linear } \\ 19 & \text { (n,d) by piece-wise linear } \\ 20 & \text { (n,t) by piece-wise linear } \\ 31 & \text { (n,gamma) by spline } \\ 32 & \text { (n,f) by spline } \\ 33 & \text { (n,p) by spline } \\ 34 & \text { (n,alpha) by spline } \\ 39 & \text { (n,d) by spline } \\ 40 & \text { (n,t) by spline }\end{array}$


The card inputs \#4, \#5, \#8, and \#9 have no meaning when piece-wise linear or spline fits are requested. It is important to note that one can only pick a single fit technique for all reactions of isotopes and that mixing the different schemes together is not possible.

The polynomial cross section fitting is handled by the POLYFI sub-program of REBUS-PC. To better guide the user on the usage of the polynomial, linear and spline fit of the cross section data, additional outputs were added to POLYFI.

\subsection{Revised Card Type 41}

The type 41 card is also used to define the polynomial cross section data fitting. A summary description of the card type is given in Figure 2-2. The purpose of card type 41 is for the user to define links between the cross section data in ISOTXS to a given "reference" ISOTXS isotope used in the A.NIP3 input.

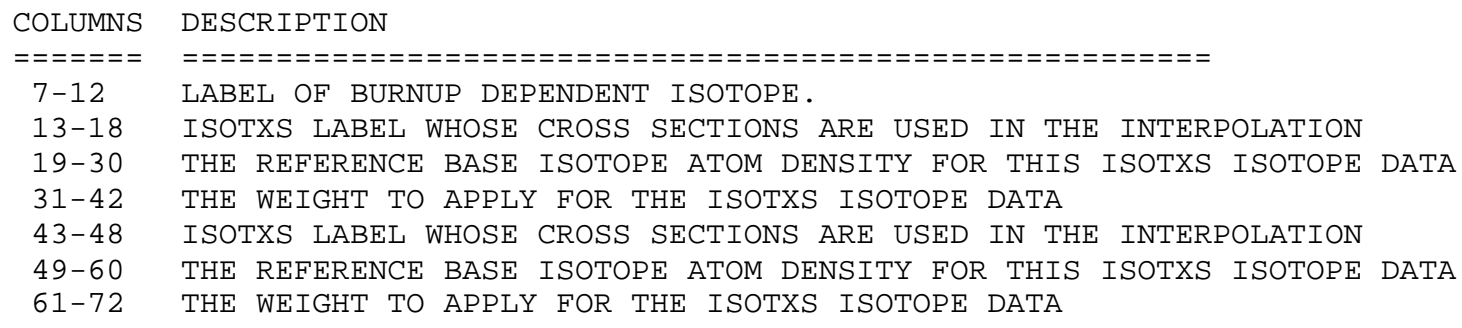

Figure 2-2. Truncated Description of Card Type \#40 in A.BURN

The fitting technique applied functionalizes the cross section data for each isotope with respect to that "reference" isotope. In a thermal spectrum system, the typical approach is to link all of the cross section data to U-235 atom density as the cross sections of the remaining isotopes will track consistently with the destruction of U-235, even for high burnup.

In REBUS-PC, this card input has been simplified for user convenience. For complex problems with many region-specific burnup dependent isotope data sets, the input for the cross section data fitting can become quite cumbersome. A quick review of Figure 2-2 shows inputs \#4 and \#7 are used to specify the atom density of the reference isotope for a given burnup dependent cross section data set. Through manipulation of the cross section generation code, the same information was made available as part of the ISOTXS data set. Thus, rather than supply reference base isotope atom density data on card type 41 fields \#4 or \#7, the user can put zeros (0.0), which triggers the REBUS-PC software to utilize the information available on the ISOTXS data file. Specifically, the POLYFI sub-program will expect to find a corresponding card type 46 and will extract the parameter ADENS from the 4D record of data set ISOTXS as the reference isotope density.

\subsection{Added Card Type 46}

Card type 46 was added to simplify the burnup dependent cross section setup. Figure 2-3 provides a summary description. As discussed in the preceding card type 41 modifications, the purpose of card type 46 is to link the burnup dependent isotope to a reference isotope in the ISOTXS data set. 


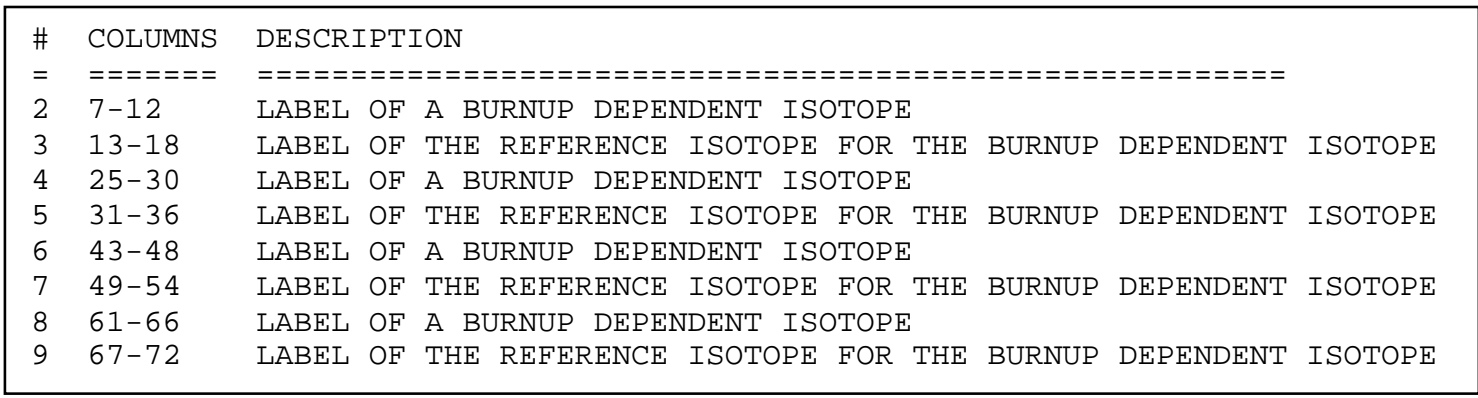

Figure 2-3. Truncated Description of Card Type \#46 in A.BURN

To fully understand how card type 46 is used, an example is presented in Figure 2-4.

\begin{tabular}{|c|c|c|c|c|c|c|c|c|}
\hline $\begin{array}{l}26 \\
41 \\
41 \\
41 \\
41 \\
41 \\
41 \\
41 \\
41 \\
41 \\
41 \\
46 \\
46 \\
46 \\
46 \\
46\end{array}$ & 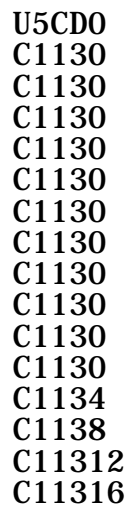 & $\begin{array}{c}\text { C1130 } \\
0 . \\
\text { C1132 } \\
\text { C1134 } \\
\text { C1136 } \\
\text { C1138 } \\
\text { C11310 } \\
\text { C11312 } \\
\text { C11314 } \\
\text { C11316 } \\
\text { C11318 } \\
\text { U5CD0 } \\
\text { U5CD4 } \\
\text { U5CD8 } \\
\text { U5CD12 } \\
\text { U5CD16 }\end{array}$ & $\begin{array}{l}1 . \\
0 . \\
0 . \\
0 . \\
0 . \\
0 . \\
0 . \\
0 . \\
0 . \\
0 . \\
\text { C1131 } \\
\text { C1135 } \\
\text { C1139 } \\
\text { C11313 } \\
\text { C11317 }\end{array}$ & $\begin{array}{l}\text { C1131 } \\
1 . \\
1 . \\
1 . \\
1 . \\
1 . \\
1 . \\
1 . \\
1 . \\
1 . \\
\text { U5CD1 } \\
\text { U5CD5 } \\
\text { U5CD9 } \\
3 \text { U5CD13 } \\
7 \text { U5CD17 }\end{array}$ & 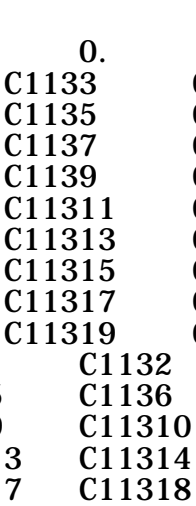 & $\begin{array}{l}0 . \\
0 . \\
0 . \\
0 . \\
0 . \\
0 . \\
0 . \\
0 . \\
0 . \\
\text { U5CD2 } \\
\text { U5CD6 } \\
\text { U5CD10 } \\
\text { U5CD14 } \\
\text { U5CD18 }\end{array}$ & $\begin{array}{l}\text { C1133 } \\
\text { C1137 } \\
\text { C11311 } \\
\text { Cl1315 } \\
\text { Cl1319 }\end{array}$ & $\begin{array}{l}\text { U5CD3 } \\
\text { U5CD7 } \\
\text { U5CD11 } \\
\text { U5CD15 } \\
\text { U5CD19 }\end{array}$ \\
\hline
\end{tabular}

Figure 2-4. Sample Input Card Type \#41 and \#46 Inputs for A.BURN

In this example, burnable isotope C1130 (Cs-113) is defined as burnup dependent with cross section data points $\mathrm{C} 1131$ to $\mathrm{C} 11318$. In the input, there are 20 total inputs for C1130 on card type 41 with 0.0 atom densities for the reference isotope. As stated, the software expects the user to provide a card type 46 input for each instance of a 0.0 atom density and will suffer a fatal error if the card type 46 data is not provided. In Figure 2-4, the model included 20 total inputs for the isotopes linked in card type 41 to C1130. As an example, the first card type 46 states that isotope C1130 should obtain its reference isotope density from isotope U5CD0 (U-235) on ISOTXS.

The output that results from including this type of input is provided in Figure 2-5. As can be seen, the POLYFI branch of the software is responsible for using the card type 40, 41, and 46 inputs. The input from Figure 2-4 that are included on card type 46 are repeated, and for each one, the software reports the atom density retrieved from the U-235 isotope on the data set. Given Cs-113 is a fission product, its expected density is considerably lower than that of the U-235 atom density seen in the output excerpt. 


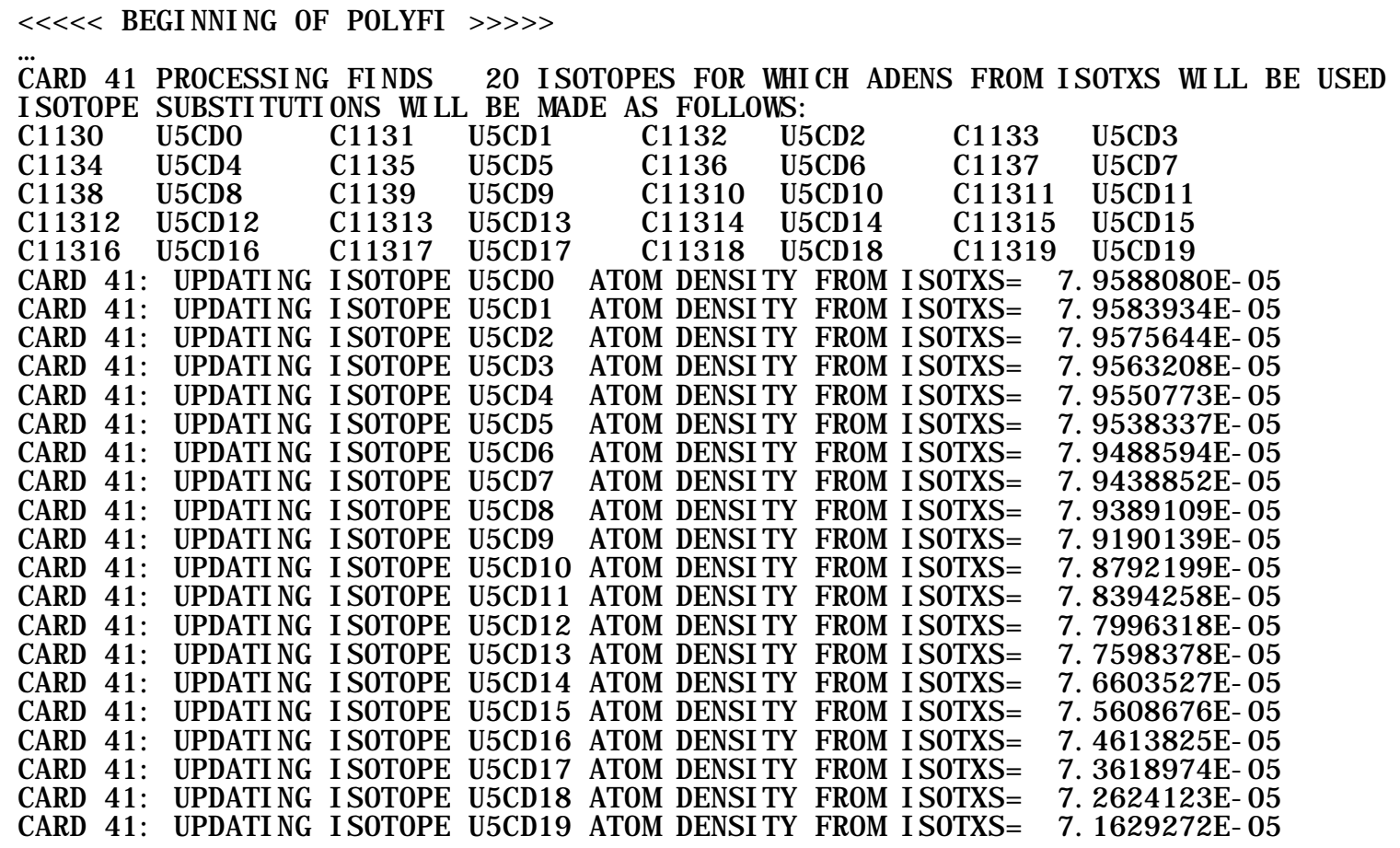

Figure 2-5. Sample Output Excerpt When Using Card Type \#41 and \#46 Inputs for A.BURN

\subsection{Revised REBUS-PC Software}

As with any source code maintenance, REBUS-PC resolves several known issues with the REBUS software and modifies the structure of the output to accommodate new needs of the analysis program. In particular, the auxiliary files in Table 2-1 were created to better summarize the output produced only by REBUS-PC.

Table 2-1. REBUS-PC Auxiliary Output Files.

\begin{tabular}{|l|l|}
\hline File Output & Description \\
\hline TYPE13.BCD & A.NIP3 card type 13,14,15 reconstitution outputs \\
\hline ATOMDEN.BCD & Atom density outputs \\
\hline CLOAD.BCD & Core loading (kg) \\
\hline K-EFF.BCD & Table of k-effective at each time node \\
\hline POLYFI.BCD & Output of polynomial or spline fitting of burnup-dependent cross sections \\
\hline POWER.BCD & DIF3D table of power data at each time node \\
\hline RXSUM.BCD & Reaction rate summary at each time node \\
\hline TFLUX.BCD & DIF3D table of flux data at each time node \\
\hline
\end{tabular}

To better facilitate the complex shuffling aspects of some reactor analysis projects, the TYPE13.BCD output file was setup to easily use its components when building a new input file. The remaining output files were created to better condense the information produced in a REBUS-PC calculation into a series of easy to read files. Because their length can become extremely large, coding changes were necessary to delete redundant data from them as the files are generated. A backspacing control routine was developed to rewind the files and overwrite the outdated information, leaving only the final data at each time point. The organization of these output files was also setup to ease its use by 
the reactor analyst. The A.STP027 card type 5 input was also modified to allow the user to skip the wrapup/restart file and not create a STACK file.

One of the known issues which was resolved with the REBUS-PC developments is the burnup edits. For many years, some of the REBUS specific edits have been slightly inconsistent with hand calculations using the power edits from DIF3D. After some work, it was determined that the origin of this problem was that REBUS was not using the same method and/or data to deduce power. For burnup, the DIF3D power edits were verified to be correct and the REBUS calculation was simply not consistent because updated zone-averaged power conversion factors were not being supplied. This problem was corrected by adding the necessary information to the COMPXS file. In REBUS-PC, the HMG4C module is now called both before and after DIF3D in order to compute the power conversion factors, which are stored on COMPXS.

Additional problems were discovered with the depletion chain, which required changes to the burn matrix formation. In short, the transmutations between fission products was not properly accounted for which is only an issue when the problem has very complex burn chains and many explicit fission products, rather than a simple lumped fission product representation. Additional problems with absorptive isotopic branching were also identified.

The path driver was modified extensively to allow REBUS-PC to process multiple cases in the ARC "block" input structure. Much like DIF3D, each new REBUS-PC calculation begins with "BLOCK=STP027." The ARC block input structure allows the user to insert datasets, modify them by replacing cards of a given card type number, or remove the cards of a given card type number, or delete the entire dataset. Standard ARC system input card options using BLOCK=, DATASET=, UNFORM=, SUBLOCK=, NOSORT=, and REMOVE=, are all described in the ARC guide [9]. The convention which is now imposed is that each new "BLOCK=" is a new problem, such that it is not possible to utilize the burned atom densities that exist at the end of block 1 to begin block 2, although one can make use of the auxiliary BCD files to construct it. Subsequent blocks can use the latest RTFLUX file (if the spatial mesh is unchanged). As a caution to the user, it is not wise to use the "no edits for the current BLOCK" option on a line "BLOCK=STP027,3" because there will be no edits of the modifications which have been made to construct the current block (these edits normally go to output files FT06 and/or FT10). Without those details, the user will not be able to verify that the problem is setup properly.

To use the restart functionality, the user must keep specific files that REBUS-PC writes during its execution. To restart a job where the user chooses not to save the STACK file, the following ARC setup should be followed:

BLOCK=OLD
DATASET $=$ ISOTXS
DATASET $=$ RESTRT
DATASET $=$ RFILES
BLOCK=STP027
UNFORM=A.SUMMAR
UNFORM=A.DIF3D
UNFORM=A.NIP3
UNFORM=A.HMG4C
UNFORM=A.BURN

To restart a job with the STACK and STKDIR files, the user should simply include 


\section{DATASET $=$ STACK \\ DATASET $=$ STKDIR}

in the "BLOCK=OLD" section of input above. Consequently, the most important files to keep are the binary files RESTRT and RFILES. Note that the existence of a STACK and STKDIR file in the local directory will actually cause REBUS-PC to assume the inputs are present. All subsequent outputs will be appended to that STACK file even if it has no connection to the current REBUS-PC calculation.

\subsection{TYPE13.BCD File Changes}

The purpose of the TYPE13.BCD dataset, as originally conceived, was to provide isotopic atom densities for all active and inactive isotopes in a REBUS-PC problem at each time node. This information can be used to construct a new REBUS-PC model, as is the case for fuel shuffling or to be used to create a time point calculation for use in DIF3D direct perturbation calculations (e. g. control rod worth). Even with this setup, the users still faced difficulties constructing a full A.NIP3 input, as they were required to produce the superfluous card type 14 inputs and the onerous composition to geometry mapping card 15. For follow on depletion calculations, the user also had to construct a set of A.BURN type 35 cards (General Fuel Management Specifications) that were consistent with the A.NIP3 types 13, 14, and 15 cards.

The TYPE13.BCD output file was modified in REBUS-PC to include all of this information for the end of the time step condition. This allows the user to construct a "snapshot" solution at any time node and relatively easily construct a fuel shuffling depletion step, provided that unique path names (card type 35) are assigned to each composition in the A.NIP3 input. To help distinguish where the card types should be placed, the labels "A.BURN" or "A.NIP3" were put in columns 74-79.

To demonstrate how to construct a "snapshot" input file, the following example is provided (where it is assumed that the user has access to a text editor and the equivalent of the Linux grep command):

1) Identify the time step in question.

a. Search in the file for "TIME NODEnnn" where nnn is the time step index).

2) Delete all previous lines from the file using the text editor

3) Search for the next occurrence of "TIME NODE" and delete all subsequent lines

4) What remains is the input for that time point

a. Save to time_node_nnn.inp

5) To separate the type 35 A.BURN lines from the rest, use grep

a. grep -i “A.BURN" time_node_nnn.inp > time_node_nnn_35.inp

b. grep -i “A.NIP3" time_node_nnn.inp > time_node_nnn_131415.inp

6) The original REBUS-PC input provided by the user can be modified to construct a new input

a. Replace all type 13,14 , or 15 cards with those in time_node_nnn_131415.inp

b. Replace all type 35 cards in A.BURN with those in time_node_nnn_35.inp

For more complicated problems, the output from several REBUS-PC executions can be merged, noting that the added cost of including all materials in the input is generally minimal. This allows the path names and A.NIP3 card type 15 and A.BURN card type 35 data to be manipulated relatively easily to allow for rather complex fuel shuffling calculations.

With inspection, the user should find that some of the TYPE13.BCD data will be tagged with "redundant if there are inactives present." These lines are always commented out (two blank initial spaces). A typical REBUS-PC calculation has both inactive (non-burnable isotopes) and active 
isotopes (those included in the depletion chain) in any given composition. In the unusual event that the problem has a burnable zone with no inactive isotopes in it, then the user must un-comment these specially tagged input lines. The reason for this layout is that there are two isolated branches of coding in REBUS-PC to treat active and inactive isotopes. The part that does the inactive isotopes provides the necessary types 13,14 and 15 cards, while the other part only deals with the active isotopes. Thus, the auxiliary type 13 cards provided as a null inactive isotope list will cause the software to skip the composition.

\subsection{Suggested User Conventions}

Given user experience with the REBUS-PC software package, the following guidelines on how to best use REBUS-PC are provided.

1) Try to use the UNFORM option for all input sections of REBUS-PC. The preceding TYPE13.BCD output are in fixed-format. and while they should match the stated input formatting, it is simply easier to use and debug free format input.

2) Check that no input lines unintentionally extend past 72 characters. The ARC software was designed around card reading technology of the late 1970s that had 72 character field inputs followed by 8 character comment fields. While an input file today can have lines with thousands of characters, ARC will truncate this data to 72 characters and any numbers that extend beyond this point can cause troubles. One typical outcome is to have unphysical densities that appear in the compositions or geometry errors associated with inconsistent spatial dimensions.

3) Try to define zone and path names that are easily connectable. Zone ZIEU01 and path PIEU01 are examples, where the $\mathrm{Z}$ denotes it as a zone and $\mathrm{P}$ as a path. One could just as easily name them both IEU01, but it has been observed that users have difficulty debugging the error messages from REBUS-PC in these circumstances.

4) REBUS-PC uses a linear flux approximation in time, which should indicate to the user that large time steps might not be accurate. For problems with important fission products that hit equilibrium (e.g. Xe-135), one should be careful to select time sizes that allow the linear approximation to accurately compute the underlying curvilinear transition regime.

A typical REBUS-PC calculation that has user input errors will generally terminate prior to performing a neutronics calculation. The regular output is directed to the ASCII file FT06 and the user should ALWAYS look in this file for the keywords ERROR, FATAL, and ${ }^{* * * *}$. REBUS-PC can execute with some users input errors that are not intended and thus produce erroneous results. The REBUS-PC error messages are numbered by subroutine and generally did not provide much additional information. An effort has been made to provide text messages that explain the reason for failure on the output at the point of failure. REBUS-PC generally notes the error and continues processing until a check for the existence of a fatal error is made where it terminates. If only a numbered message such as "ERROR NUMBER 10010 IN SUBROUTINE X" is provided, the user can contact appropriate staff at ANL to get further direction on the execution issues.

The REBUS-PC output is driven by many different modules from which the job can be terminated due to an input error. The module is identified by the page header with a title such as DIF3D, GNIP4C (general neutronics input processor), HMG4C (cross section homogenization processor), FCI002 (fuel cycle input processor), FCC004 (fuel cycle computational module), POLYFI (burnup-dependent neutron cross section fitting module), etc... If the job involves burnup-dependent neutron cross sections and the POLYFI module is reporting the error, the user likely made an error in the 
specification of the A.BURN cards associated with the burnup dependent cross section. The auxiliary file POLYFI.BCD can be looked at for a more thorough error description as appropriate.

Only as a last resort should the user enable the "debug flag" of a given module that has an error. If chosen, the output file will be very extensive and can detail the specific point in the execution where REBUS-PC encounters the fatal error. In most cases it is suggested the user contact appropriate staff at ANL before resorting to this approach.

One of the more challenging aspects of using an older technology software like REBUS-PC is dealing with the container allocation. These problems can be identified in the output of REBUS as "insufficient storage requirements" and refer to the inputs from the user dealing with SCM (also referred to as FCM) or LCM (also referred to as ECM) containers. The maximum values REBUS-PC can allocate and use in any container is $\sim 250$ million which corresponds to $\sim 2 \mathrm{~GB}$ of memory. The A.DIF3D input is the primary point where the allocation is decided although all other modules that are given larger numbers are allowed to resize the container. From the A.DIF3D card type 02 input description, it is suggested that the user put 50 million in for the FCM container size and 150 million words in the ECM container size when using REBUS-PC. These numbers correspond to 1.5 GB of memory and are generally more than sufficient for all DIF3D based calculations. If sufficient computing resources are present ( $>>4$ GB of memory), one could also simply put 250 million words for all container inputs in all relevant input container cards of REBUSPC. 


\section{Verification of the REBUS-PC Modifications}

REBUS-PC has been subjected to an ongoing process of software verification, where new changes are introduced and verified to function properly. The validation of the REBUS-PC software is typically specific to a given reactor type and REBUS-PC has consistently been shown to produce depletion results consistent with many different reactors over the years. Many sample problems are provided in the distribution which verifies that the provided software is working properly and users can refer to the verification of REBUS-PC in Reference 10.

With the stated changes above, the following sections are presented to demonstrate the software changes introduced in REBUS-PC v. 1.5 relative to v. 1.4 are working as intended.

\subsection{Verification of the Cubic Spline Fit of Burnup-Dependent Cross Sections}

The Mathematica software was used to duplicate the REBUS-PC cubic spline and polynomial fit algorithms for the purposes of comparison and to assist in debugging. As mentioned, the cubic spline technique is suggested noting that the performance is not impacted significantly, as the computational effort required in DIF3D to solve for the flux constitutes a bulk of the overall effort. This section covers the basic algorithm and discusses the verification work that went into verifying the interpolation.

In some cases, lumped fission product cross section data sets can produce problems for REBUS-PC. Assuming that the original cross section data is non-negative, the typical manifestation is that the data fit will generate negative cross sections. Both spline and polynomial fits have been observed to go negative when a particular cross section does not vary smoothly. REBUS-PC will often terminate due to lack of convergence or if invalid macroscopic cross section data is obtained. To overcome this problem, the "piecewise linear" fit option was added, which is obtained by zeroing out the second derivative terms in the spline fit methodology. If the user observes the stated problems with negative cross sections, then this fitting scheme should be used as an alternative.

The polynomial fit is not suggested for use, as in most cases it does not reproduce the zero burnup point (without applying a special weighting for that point). Hence the "all fresh fuel" eigenvalue is typically not the same as using burnup-dependent cross sections, as the polynomial fit is not guaranteed to go through all user provided cross section points.

Table 3-1 provides the eigenvalue results for a reactor model using the two different cross section interpolation routines. In this example, the impact of burnup-dependent cross section data is not large and both schemes yield practically the same eigenvalue results, noting that the atom densities will only be impacted in the $4^{\text {th }}$ or $5^{\text {th }}$ significant digit. As stated, the spline fitting process is more trusted, as the interpolation is guaranteed to go through the data points. This is clearly displayed in this example, as the polynomial interpolation has a large error at the first time point. 
Table 3-1. Eigenvalue Results Using Burnup-Dependent Cross Sections

\begin{tabular}{|c|c|c|c|}
\hline \multirow{2}{*}{$\begin{array}{c}\text { Time } \\
\text { (days) }\end{array}$} & \multicolumn{2}{|c|}{ keff } & $\begin{array}{c}\text { Fitting } \\
\text { Scheme } \\
\text { difference } \\
\text { (pcm) }\end{array}$ \\
\cline { 2 - 3 } & Polynomial & Cubic spline & \\
\hline 0.00 & 1.053209 & 1.053503 & -29.4 \\
\hline 0.33 & 1.039278 & 1.039424 & -14.6 \\
\hline 1.00 & 1.026924 & 1.026942 & -1.8 \\
\hline 1.33 & 1.035560 & 1.035615 & -5.5 \\
\hline 2.00 & 1.023934 & 1.023955 & -2.1 \\
\hline 2.33 & 1.034912 & 1.034973 & -6.1 \\
\hline 3.00 & 1.023365 & 1.023391 & -2.6 \\
\hline 3.33 & 1.034537 & 1.034605 & -6.8 \\
\hline 4.00 & 1.022979 & 1.023009 & -3 \\
\hline 4.33 & 1.034165 & 1.034240 & -7.5 \\
\hline 7.00 & 1.049590 & 1.049673 & -8.3 \\
\hline 7.33 & 1.037271 & 1.037349 & -7.8 \\
\hline
\end{tabular}

\subsection{Verification of the TYPE13.BCD Dataset}

The easiest way to test the TYPE13.BCD output is to simply use it and reproduce the REBUS-PC computed result. As an example, using the preceding BMRR test case, it is evident that the cubic spline fit results in an end-of-cycle $k_{\text {eff }}$ of 1.037349 at 7.33 days, as seen in Table 3-1. The output from the TYPE13.BCD file at 7.33 days was then read and a new input deck with a "zero burnup" time step was constructed. Using REBUS-PC, that input deck yielded a keff of 1.037352, which is within the input convergence tolerance of $1 \times 10^{-5}$. This process, of creating a snapshot input file, is extremely easy and quick to perform.

\subsection{Verification Test Suite}

Because REBUS-PC has been continuously developed and maintained, there are a considerable number of test cases that are available for it. Further, there has been considerable validation work for multiple reactors during its existence. For this reason, the user is referred to the companion documents provided with the REBUS-PC software and encouraged to contact appropriate staff at ANL with any questions about additional verification and validation documentation. 


\section{Known Limitations}

With respect to the originating REBUS software, there are several modifications made to REBUS-PC that prevent some of the features from working. In addition, there are known restrictions which do not allow the intended features of REBUS-PC to work on certain targeted problems.

Almost all fuel cycle analysis software model a standard depletion step. In such a scenario, the fuel compositions are known at the beginning of the time step and the objective is to calculate the updated fuel compositions at the end of the time step for a given power level. Fuel shuffling is performed at each shutdown point between depletion time steps. This is termed a "non-equilibrium fuel cycle analysis," as each progressive time point presents a unique fuel loading and thus unique solution. This is the typical operation of both commercial and test reactors, as inadvertent shutdowns, load demand, fuel failure, and other unpredictable aspects of operation reduce the reactor from its ideal performance level.

For reactor design purposes, it is generally advantageous to rapidly study the behavior of a reactor system under a proposed repetitive fuel management scheme. This is termed an "equilibrium cycle analysis," as it obtains the equilibrium behavior of the reactor and assumes the reactor state repeats at regular intervals. The REBUS software [5] was designed to model both non-equilibrium and equilibrium analysis modes and continues to do both today. Due to source code changes, the REBUS-PC software does not presently allow the equilibrium mode calculation to execute. This action also disables the fuel fabrication and reprocessing features of the REBUS software.

Additional known limitations have been identified and are associated with the problem size. In some specific cases, the REBUS-PC software is known to fail with a memory fault or, in worse situations, simply produce erroneous output. An example output termination message from REBUS-PC for the memory fault error is shown in Figure 4-1. This issue has been identified as a memory leak in the HMG4C module and will be corrected in the next release of REBUS-PC.

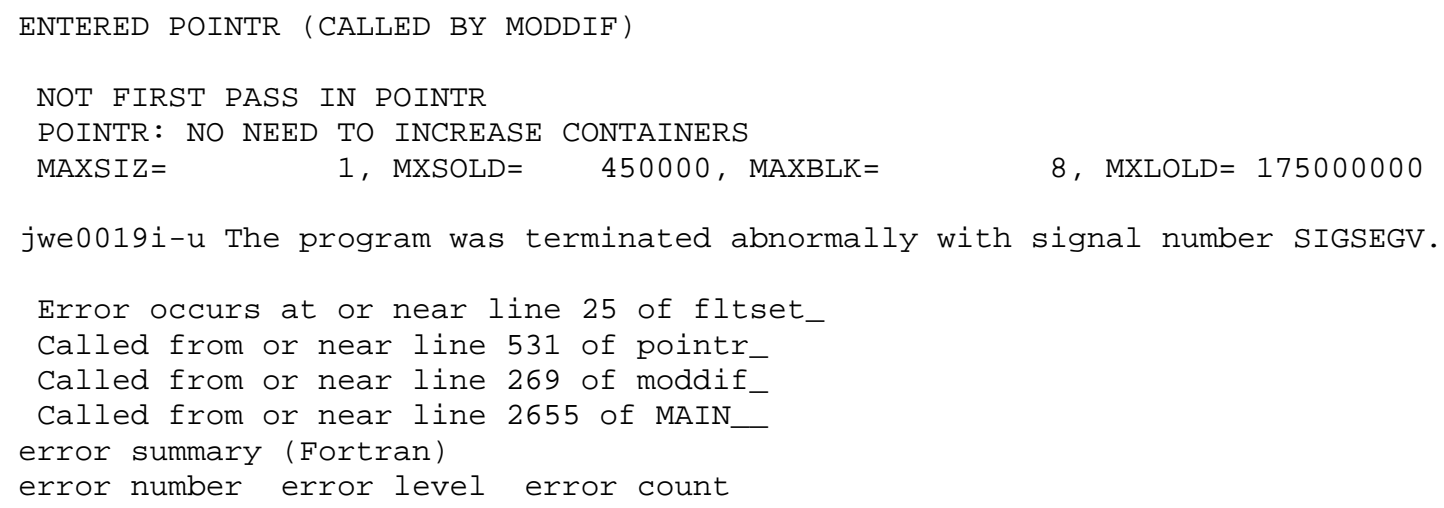

Figure 4-1. Output Termination Message from REBUS-PC for Memory Fault Error

However, as stated, in some cases the REBUS-PC software will complete execution with no error message and simply produce erroneous results. Those results are generally obvious as the eigenvalue results are skewed unrealistically or negative capture rates or fluxes appear in the output. One easy way to check a suspected erroneous case is to do a state point calculation using DIF3D based upon the REBUS-PC output, as described earlier in this report, which should produce the identical keffective result of the REBUS-PC time point. If this does not occur, then the HMG4C memory access 
might be to blame and it is suggested that the user contact staff at ANL for further guidance and support. 


\section{Conclusions}

The needs of the research reactor analyst continue to evolve as reactor design and models become more complex. Software for reactor analysis must evolve to meet those needs, as well as grow such that the software can be used on modern computing platforms.. This report discusses the modifications made to the REBUS software to produce REBUS-PC Version 1.5, including the introduction of spline cross section fits to improve the burnup dependent cross section methodology. It serves as an addendum to the latest REBUS software manual [5], to support users of REBUS-PC. 


\section{Acknowledgement}

This work was sponsored by the U.S. Department of Energy, Office of Material Management and Minimization in the U.S. National Nuclear Security Administration Office of Defense Nuclear Nonproliferation under Contract DE-AC02-06CH11357. 


\section{References}

1. J. Hoover, G. K. Leaf, D. A. Meneley, and P. M. Walker, "The Fuel Cycle Analysis System, REBUS," Nucl. Sci. Eng. 45, p. 53, 1971.

2. A. P. Olson, J. P. Regis, D. A. Meneley, and L. J. Hoover, "A User's Manual for the Reactor Burnup System, REBUS," FRA-TM-41, Argonne National Laboratory, September 28, 1972.

3. A. P. Olson, "A User's Manual for the Reactor Burnup System, REBUS-2," FRA-TM-62, Argonne National Laboratory, March 1, 1974.

4. R. P. Hosteny, "The ARC System Fuel Cycle Analysis Capability, REBUS-2," ANL-7721, Argonne National Laboratory, October 1978.

5. B. J. Toppel, “A User's Guide for the REBUS-3 Fuel Cycle Analysis Capability,” ANL-83-2, Argonne National Laboratory, 1983.

6. K. L. Derstine, "DIF3D, A Code to Solve One-, Two-, and Three-Dimensional Finite-Difference Diffusion Theory Problems," ANL-82-64, Argonne National Laboratory, 1984.

7. G. Palmiotti, E. E. Lewis, and C. B. Carrico, "VARIANT: VARIational Anistropic Nodal Transport for Multidimensional Cartesian and Hexagonal Geometry Calculation," ANL-95/40, Argonne National Laboratory, October 1995.

8. Lahey/Fujitsu Fortran 95 Language Reference, Revision F, Lahey Computer Systems, Inc. Incline Village, NV, 2000 (Linux Pro 6.0).

9. C. H. Adams et al., "The Utility Subroutine Package used by the Applied Physics Division Export Codes," ANL-83-3, Argonne National Laboratory, April 1983.

10. P. Deng, et. al., "REBUS-PC v1.5 Verification Test Summary," ANL/RTR/TM-19/12, Argonne National Laboratory, September 2019. 


\section{APPENDIX: A.BURN DATASET CHANGES}

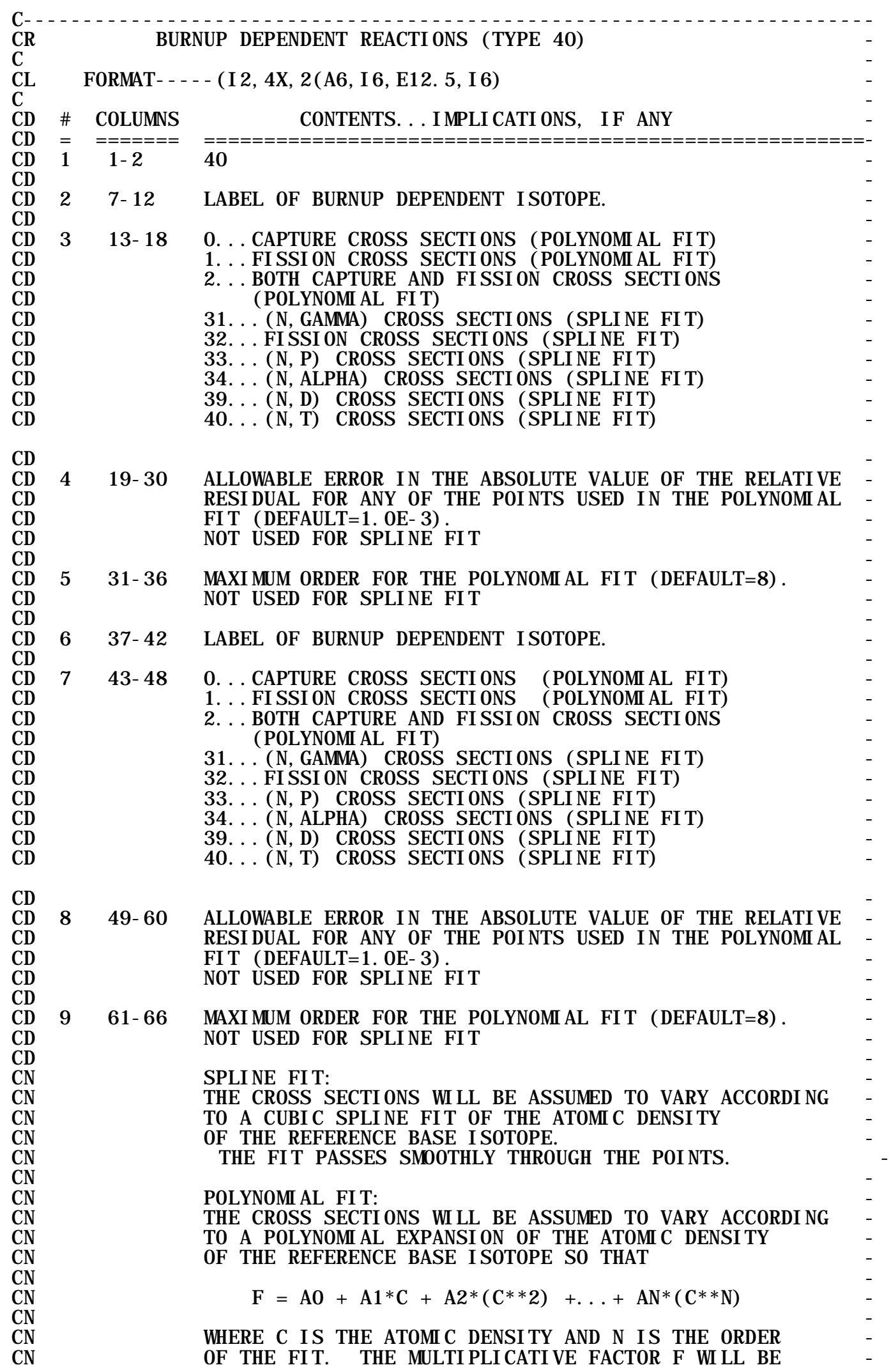




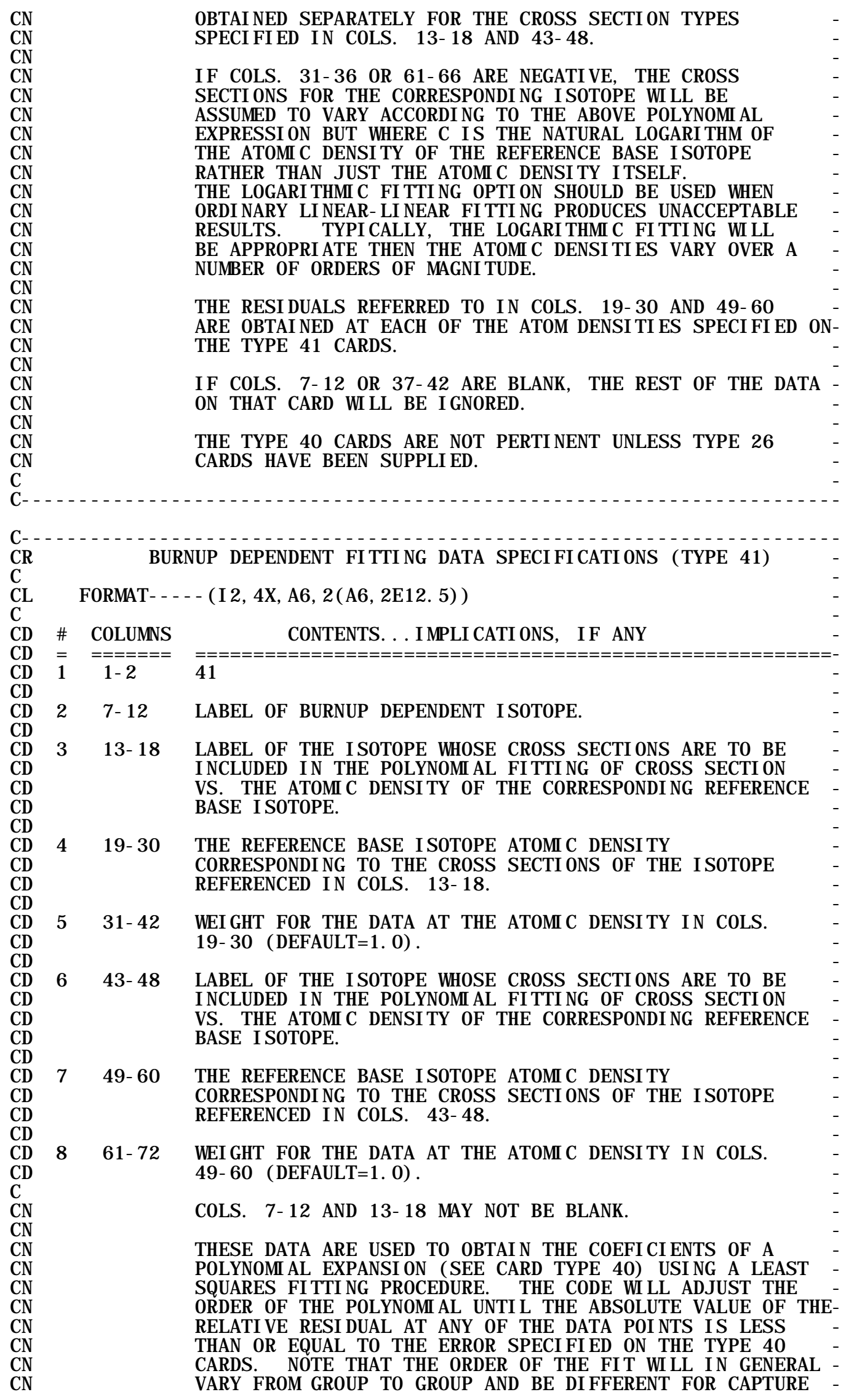




\begin{tabular}{|c|c|c|c|c|}
\hline $\mathrm{CN}$ & & & AND FI SSI ON. & \\
\hline $\begin{array}{l}\mathrm{CN} \\
\mathrm{CN} \\
\mathrm{CN} \\
\mathrm{CN} \\
\mathrm{CN} \\
\mathrm{CN} \\
\mathrm{CN} \\
\mathrm{CN} \\
\mathrm{CN}\end{array}$ & & & 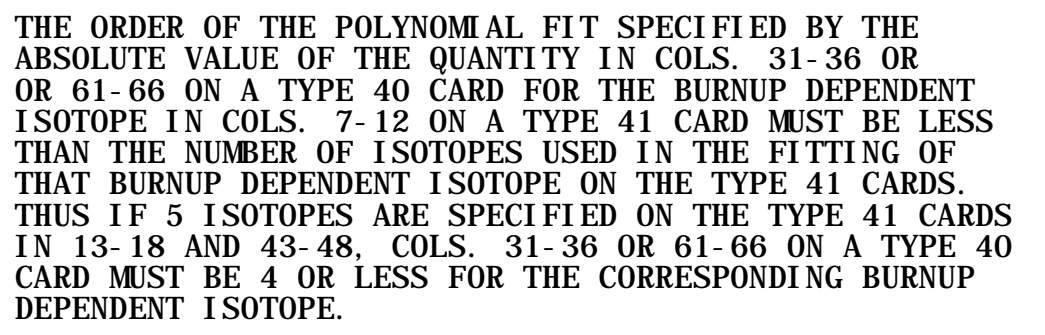 & \\
\hline $\begin{array}{l}C N \\
C N \\
C N \\
C N \\
C N \\
C N\end{array}$ & & & $\begin{array}{l}\text { NOTE THAT CONTRARY TO THE I SOTOPES SPECI FI ED ON THE } \\
\text { TYPE } 26 \text { CARDS, THE I SOTOPES USED FOR THE FI TTI NG } \\
\text { SPECI FIED I N COLS. 13- } 18 \text { AND } 43-48 \text { ARE NORMALY NOT } \\
\text { I NCLUDED I N THE REBUS- } 3 \text { CALCULATI ON PER SE. THUS, THE } \\
\text { LABELS I N COLS. 13- } 18 \text { AND 43- 48 NORMALLY W WL NOT } \\
\text { APPEAR ON THE TYPE O9 OR 10 CARDS NOR ON THE TYPE } 13 \\
\text { AND/ OR TYPE } 14 \text { CARDS OF DATA SET A. NI P3. }\end{array}$ & \\
\hline $\begin{array}{l}\text { CN } \\
\mathrm{CN} \\
\mathrm{CN} \\
\mathrm{CN} \\
\mathrm{CN}\end{array}$ & & & $\begin{array}{l}\text { I F THE ATOM C DENSI TY DURI NG THE COURSE OF THE PROBLEM } \\
\text { FALLS OUTSI DE THE RANGE OF DENSI TI ES SPECI FI ED ON THE } \\
\text { TYPE } 41 \text { CARD FOR THE PARTI CULAR REFERENCE BASE I SOTOPE, } \\
\text { THE PROBLEM W LL BE TERM NATED W TH A FATAL ERROR } \\
\text { MESSAGE. }\end{array}$ & \\
\hline $\begin{array}{l}\text { CN } \\
\mathrm{CN} \\
\mathrm{CN}\end{array}$ & & & $\begin{array}{l}\text { IF A WEI GHT OF 0. O I S DESI RED, THAT VALUE MUST BE USED } \\
\text { EXPLI CI TLY I N COLS. 31-42 OR 61- } 72 \text { SI NCE A WEI GHT OF } \\
1.0 \text { W LL BE USED I F THOSE COLUMNS ARE LEFT BLANK. }\end{array}$ & \\
\hline CN & & & $\begin{array}{l}\text { THE TYPE } 41 \text { CARDS ARE NOT PERTI NENT UNLESS TYPE } 26 \\
\text { CARDS HAVE BEEN SUPPLI ED. }\end{array}$ & \\
\hline $\begin{array}{l}C N \\
C N \\
C N \\
C N \\
C N \\
C N \\
C N \\
C N \\
C N \\
C N \\
C N \\
C N \\
C N \\
C N \\
C \\
C-\end{array}$ & & & 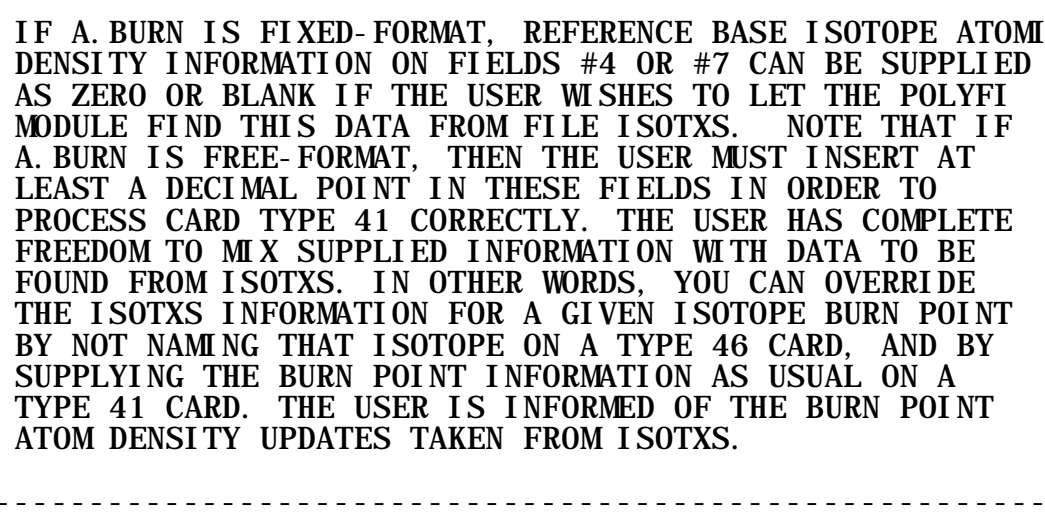 & \\
\hline $\begin{array}{ll}\mathrm{Cl}-\mathrm{C}^{-} \\
\mathrm{C} \\
\mathrm{CL}\end{array}$ & & FORMAT- - - & $\begin{array}{l}\text { NUP DEPENDENT FI TTI NG I SOTXS LABELS (TYPE 46) } \\
-(12,4 \mathrm{X}, \mathrm{A6}, 2(\mathrm{A6}, 2 \mathrm{E} 12.5) \text { ) }\end{array}$ & \\
\hline CD & & COLUMNS & CONTENTS. . . I MPLI CATI ONS, I F ANY & \\
\hline CD & & $1-2$ & 46 & \\
\hline $\begin{array}{l}C D \\
C D \\
C D\end{array}$ & 2 & 7- 12 & $\begin{array}{l}\text { LABEL OF BURNUP DEPENDENT I SOTOPE WHOSE BURNUP DEPENDS } \\
\text { ON THE ATOM DENSI TY OF THE LABEL I N FI ELDS } 3 \text {. }\end{array}$ & \\
\hline $\begin{array}{l}C D \\
C D\end{array}$ & 3 & 13- 18 & $\begin{array}{l}\text { LABEL OF THE I SOTOPE WHOSE ATOM DENSI TY DETERM NES } \\
\text { CROSS SECTI ONS FOR I SOTOPE I N FI ELD } 2 .\end{array}$ & \\
\hline CD & 6 & $25-30$ & SAME AS FI ELD 2. & \\
\hline CD & 5 & $31-36$ & SAME AS FI ELD 3. & \\
\hline CD & 6 & 43- 48 & SAME AS FI ELD 2. & \\
\hline
\end{tabular}




\begin{tabular}{|c|c|c|c|}
\hline \multicolumn{4}{|r|}{ AME AS FI ELD 3.} \\
\hline CD & 8 & $61-66$ & SAME AS FI ELD 2. \\
\hline $\begin{array}{l}C D \\
C D \\
C\end{array}$ & 7 & $67-72$ & SAME AS FI ELD 3. \\
\hline $\begin{array}{l}C N \\
C N \\
C N \\
C N \\
C N \\
C N \\
C N \\
C N \\
C N \\
C N \\
C N\end{array}$ & & & 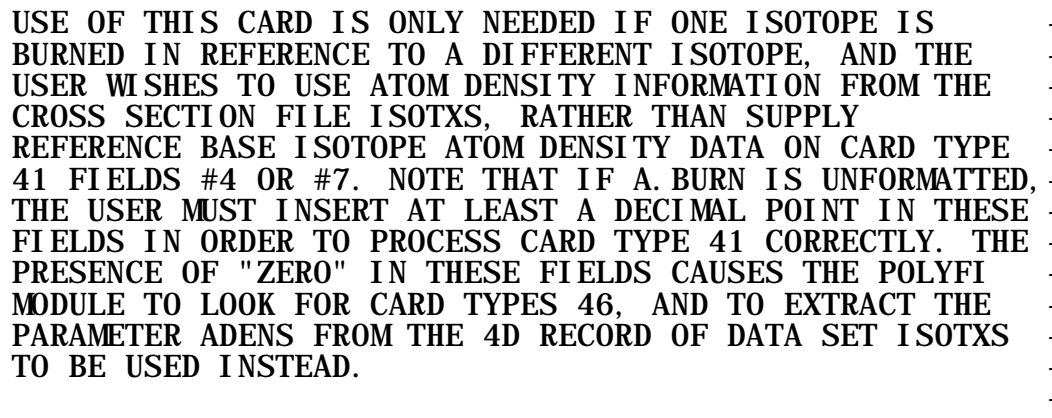 \\
\hline
\end{tabular}




\section{Argonne}

Nuclear Science \& Engineering Division

Argonne National Laboratory

9700 South Cass Avenue, Bldg. 208

Argonne, IL 60439

www.anl.gov

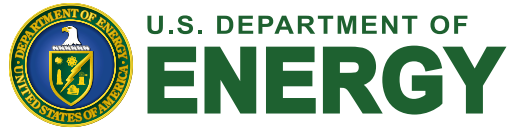

Argonne National Laboratory is a U.S. Department of Energy laboratory managed by UChicago Argonne, LLC 